\title{
TEORIA DO ESTADO E GLOBALIZAÇÃO: PESQUISA EM MOVIMENTO PARA A CRÍTICA DA DOGMÁTICA
}

\author{
Marcus Vinícius Araújo Batista de Matos* \\ Priscila Vieira e Souza**
}

Sumário: 1 Introdução; 2 A problemática da compreensão doutrinária e tradicional do Estado nas disciplinas do ensino jurídico; 3 O problema metodológico: a ciência centralizada no Estado-nação; 4 Conclusões: por uma reformulação da crítica do Estado e do Direito.

Resumo: Este artigo trata das formas de compreensão, noções e conceitos utilizados para o conhecimento do Estado no ensino do Direito no Brasil, observados na obra de autores e textos doutrinários tradicionais na disciplina Teoria Geral do Estado (Ciência Política), como descrita pelo Ministério de Educação - MEC. A partir de problemas apontados na formação acadêmica do estudante de Direito, aborda consequências da adoção acrítica de "conceitos zumbis", carregados de conteúdos ideológicos e centrados em concepções de Estado e "instituições-casca" inadequadas à realidade das transformações ocorridas no Estado, durante o século XXI. Propõe uma revisão metodológica da Teoria do Estado a partir da crítica do nacionalismo metodológico e da perspectiva do Estado-nação, conforme abordagens de Ulrich Beck e Anthony Giddens.

Palavras-chave: Teoria do Estado. Estado Nação. Globalização. Ensino Jurídico.

\footnotetext{
* Doutorando em Direito (MPhil/PhD) pelo Birkbeck College, University of London. Mestre em Direito pelo Programa de Pós-graduação em Direito da Universidade Federal do Rio de Janeiro - PPGD/UFRJ (2011), na linha de pesquisa Sociedade, Direitos Humanos e Arte. Bacharel em Direito pela Universidade Federal do Rio de Janeiro - UFRJ (2007). Atualmente é Bolsista da CAPES pelo Programa de Doutorado Pleno no Exterior. Professor de Direito Constitucional, Direito Administrativo e Teoria do Direito.

** Doutoranda pela Escola de Comunicação da Universidade Federal do Rio de Janeiro - UFRJ. Mestre pelo mesmo Programa (2011). Formada na Universidade Estadual de Ponta Grossa - UEPG.
} 


\section{Introdução}

As reflexões que conduziram a este artigo tiveram sua origem em 2006, sendo sistematizadas, pela primeira vez, por ocasião da XXIX Jornada de Iniciação Científica da Universidade Federal do Rio de Janeiro (UFRJ). ${ }^{1}$ Trata-se de um duplo esforço de sistematização, uma vez que tais reflexões foram produzidas coletivamente e ao longo de um vasto período de tempo, reunindo colaborações oriundas de debates e atividades acadêmicas realizadas com alunos do curso de graduação em Direito da UFRJ. Ao mesmo tempo, quase que reflexivamente, estes debates eram alimentados por leituras que os autores fizeram em contextos institucionais diferentes - a UFRJ e a Universidade Federal do Paraná (UFPR) sobre o objeto deste artigo: as diferentes possibilidades de compreensão e acesso à noção de "Estado", vagamente conceituada nos textos mais comumente aceitos na disciplina de "Teoria Geral do Estado/Ciência Política"(TGE) - disciplina presente com maior frequência nos currículos de formação dos cursos de graduação em Direito, do que nas ciências sociais ou demais cursos de ciências sociais aplicadas.

O primeiro grupo de reflexões sistematizadas remete às atividades de monitoria ${ }^{2}$ da disciplina de TGE orientada pelo Prof. Dr. José Ribas Vieira, na Faculdade Nacional de Direito da Universidade Federal do Rio de Janeiro (FND/UFRJ), durante o ano de 2006. Ao longo de dois períodos letivos acadêmicos foram propostas atividades complementares semanais de monitoria, tendo participação ativa de aproximadamente quarenta estudantes, iniciantes no curso de Direito. Para tanto, os monitores realizaram leituras e fichamentos de livros e autores ${ }^{3}$ utilizados no ensino da TGE e, posteriormente, por indicação do Prof. Dr. José Ribas Vieira, buscaram debater e repensar os marcos e conceitos levantados por estes "clássicos" da

1 DE MATOS, Marcus V. A. B.; SOUZA, Priscila V.; DEMIDOFF, Alexandre. O. Novos paradigmas para a Teoria Geral do Estado: A contribuição da Sociologia contemporânea. In: Jornada Giulio Massarani de Iniciação Científica, Artística e Cultural da UFRJ, 29., 2007, Rio de Janeiro. Anais... Rio de Janeiro: UFRJ, 2007. p. 359.

2 DE MATOS, Marcus V. A. B. Resumo do Plano de Atividades do Monitor. Disciplina de Teoria Geral do Estado. Faculdade Nacional de Direito. Universidade Federal do Rio de Janeiro: Rio de Janeiro, 2006.

3 Entre os vários autores de TGE consultados, destacamos aqueles que constavam na ementa da disciplina TGE do Curso de Graduação em Direito da UFRJ e que, provavelmente em virtude deste fato, tinham vários exemplares de seus livros disponíveis para consulta na Biblioteca Carvalho de Mendonça: BONAVIDES, Paulo. Ciência Política. 9. ed. Rio de Janeiro: Forense, 1993; DALLARI, Dalmo de Abreu. Elementos de teoria geral do Estado. 23. ed. São Paulo: Saraiva, 2002; MALUF, Sahid. Teoria Geral do Estado. 26. ed. São Paulo: Saraiva, 2003; também importante neste primeiro momento, foi a obra: BOBBIO, Norberto. Estado, Governo, Sociedade: por uma teoria geral da política. Rio de Janeiro: Paz e Terra, 1987. 
TGE a partir de críticas da Sociologia Política contemporânea.

Um segundo grupo de reflexões aqui sistematizadas diz respeito aos debates, leituras e pesquisas desenvolvidas já no âmbito do Grupo de Pesquisa em Teoria do Estado e Globalização (GPTEG), durante o ano de 2007. Estas reflexões se iniciaram com projeto de pesquisa ${ }^{4}$ sob a orientação dos Professores José Ribas Vieira (UFRJ) e Pedro Rodolfo Bodê de Moraes (UFPR), e se desenvolveram em nove atividades acadêmicas ${ }^{5}$ de debate, leituras e apresentações de resenhas e fichamentos, já sob coordenação e participação da Prof ${ }^{a}$. Luciane Soares da Silva, atual professora associada da Universidade Estadual do Norte Fluminense (UENF).

Como pressupostos ${ }^{6} \mathrm{em}$ comum, tanto aquele projeto quanto este artigo assumem dois pontos de partida: em primeiro lugar, que o Estado Moderno no Século XXI passaria por uma série de transformações que o colocariam em crise; depois, que para compreender estas transformações seria necessário utilizar um outro arcabouço teórico reflexivo, uma vez que a produção acadêmica e conceitual de uma realidade anterior poderia não ser adequada para este novo momento. Desta maneira, a pesquisa sistematizada aqui aposta na contribuição da sociologia política contemporânea para a formação em Teoria do Estado, centrada na compreensão das transformações ocorridas no Estado a partir da segunda metade do século XX.

Embora, atualmente, parte dos argumentos aqui expostos tenha já novos contornos no âmbito do Grupo de Pesquisa em Teoria do Estado e Globalização (GPTEG) ${ }^{7}$, este artigo preserva e se limita a trabalhar a partir das reflexões originárias do grupo que, posteriormente, viriam a servir de base para a fundamentação teórica e definição dos objetivos, linhas de pesquisa e projetos atuais do GPTEG.

4 DEMIDOFF, A. O.; DE MATOS, M. V. A. B.; MAGALDI, T.; SOUZA, P. V. Novos paradigmas para a Teoria Geral do Estado: a contribuição do pensamento de Ulrich Beck, Anthony Giddens e Giorgio Agamben para a compreensão do Estado no Século XXI. Projeto de Pesquisa. Universidade Federal do Rio de Janeiro - UFRJ. Rio de Janeiro, 2007. 29 p.

5 GRUPO DE PESQUISA EM TEORIA DO ESTADO E GLOBALIZAÇÃO - GPTEG. Relatório de Atividades Acadêmicas. Universidade Federal do Rio de Janeiro - UFRJ. Rio de Janeiro, 2007, 5p.

6 É interessante observar que pressupostos semelhantes levaram a esforços teóricos similares, empreendidos em período próximo a esta pesquisa, por professores e pesquisadores da UFPR. Neste sentido, ver: FONSECA, Ricardo Marcelo (Org.). Repensando a Teoria do Estado. Belo Horizonte: Fórum, 2004.

7 O GPTEG é composto por pesquisadores e colaboradores da UFRJ, da UFPR e da Pontifícia Universidade Católica do Rio de Janeiro (PUC-Rio). Atualmente, é dividido em três linhas de pesquisa que abordam os seguintes temas: "Modernidade, crise das instituições e o novo constitucionalismo latino-americano"; "Estado, Mídia e Cultura"; "Controle Social e Estado de Exceção". Para maiores informações, ver: http://teoriadoestado.blogspot.com 
Nosso objetivo, portanto, é contribuir para uma reflexão crítica do Estado, levantando questionamentos e nos detendo naquelas poucas respostas que podemos encontrar na investigação do fenômeno políticoestatal. Para tanto, é imprescindível considerar as transformações que o Estado tem sofrido desde o final do século XX, quando, em tese, deixa de protagonizar os principais acontecimentos políticos mundiais. Essas mudanças acarretam um suposto enfraquecimento do Estado nacional, dos partidos políticos e de outras instituições neles fundamentadas, abrindo um espaço que, hoje, tem sido ocupado por organizações internacionais, organizações não-governamentais - ONGs, movimentos sociais e uma pluralidade de representações daquilo que podemos chamar de uma sociedade civil internacional - ainda em formação.

Os mecanismos para a compreensão desse Estado, em decadência e transição, é que são os objetos primordiais de análise deste artigo, que se concentra nas propostas de análise destes fenômenos a partir da obra dos sociólogos Ulrich Beck e Anthony Giddens.

\section{A problemática da compreensão doutrinária e tradicional do Estado nas disciplinas do ensino jurídico}

Amera indicação da necessidade de reformulação do ensino jurídico brasileiro não se constitui em nenhuma novidade. Há inúmeras discussões em curso no que tange ao ensino, à pesquisa e à atividade jurisdicional sob a ótica universitária. Todavia, mesmo com algum avanço, boa parte dos currículos acadêmicos de Direito ${ }^{8}$ encontram-se defasados, não só em relação ao ensino jurídico no exterior, como também em face da necessidade de desenvolver pesquisas científicas metodologicamente coerentes ${ }^{9}$, e reflexões consistentes sobre a prática jurídica e sua complementaridade com o fenômeno político no século XXI.

Em particular, essa situação se torna sensível quando analisamos o ensino da disciplina intitulada pelo Ministério da Educação (MEC) como Teoria Geral do Estado (Ciência Política). Com nome já controverso, a história do ensino

\footnotetext{
8 Neste sentido, cf. VIEIRA, José Ribas. Instrumentos e experiências acadêmicas: a busca do perfil de pesquisa nos programas de pós-graduação em Direito. Revista da Faculdade de Direito de Campos, ano VII, n. 9, p. 103-117, dez. 2006. Disponível em: < http://www.fdc.br/Arquivos/ Mestrado/Revistas/Revista09/Artigos/JoseRibas.pdf>. Acesso em: out. 2011.

9 Ver, a exemplo desta discussão: VIEIRA, J. R.; FIGUEIRA, Luiz Eduardo; REMY, A. S.; LIPPI, C. S.; IGREJA, C. O.; SILVA, C. P. C.; CARVALHO, F. M.; ISRAEL, J. K.; DE MATOS, Marcus V. A. B.; PIRES, Nádia; RESENDE, N. C.; NOGUEIRA, R. F.; SANTANNA, T. L. Aulas do Curso de Metodologia Jurídica do Programa de Pós-graduação em Direito da Universidade Federal do Rio de Janeiro (PPGD/UFRJ). Rio de Janeiro: Faculdade Nacional de Direito, 2009 (Apostila).
} 
dessa disciplina, por si só, poderia ser alvo de tantas discussões quantas as que se debruçam hoje sobre o destino do ensino jurídico. De fato, trata-se de uma das cadeiras mais fundamentais ao ensino do Direito, presente em quase a totalidade das faculdades como disciplina básica para a compreensão do Estado e, supostamente, para suas relações com o Direito.

Inicialmente identificada como Direito Constitucional, é em meados do século XX que adquire a denominação de Teoria Geral do Estado (TGE). Dessa fase, dadas as suas características por demais densas e, sobretudo, seu conteúdo variável e extenso para uma única disciplina, o professor Pedro Calmon ${ }^{10}$ dizia que "uma Teoria do Estado será pois, queira ou não o jurista, um roteiro de opinião obstinada". Uma breve leitura da obra citada mostra-nos que o conteúdo então exposto na disciplina trazia mais elementos filosóficos e ideológicos do que propriamente preocupações conceituais científicas.

Contudo, o ensino de TGE se transforma e incorpora tantos elementos que, sob o aspecto de uma metodologia científica rigorosa, dificilmente seria aceito como tendo embasamento científico. Dalmo de Abreu Dallari ${ }^{11}$ provavelmente o autor mais lido nos cursos de Direito para a disciplina em questão - dissertando sobre os métodos utilizados em TGE, assim os explica:

Fixando-se, em largos traços, a noção de Teoria Geral do Estado, pode-se dizer que ela é uma disciplina de síntese, que sistematiza conhecimentos jurídicos, filosóficos, sociológicos, políticos, históricos, antropológicos, econômicos, psicológicos, valendo-se de tais conhecimentos para buscar o aperfeiçoamento do Estado, concebendo-o, ao mesmo tempo, como um fato social e uma ordem, que procura atingir os seus fins com eficácia e com justiça.

A consequência direta de uma disciplina que elege como objeto "o estudo do Estado sob todos os aspectos" 12 é o risco de naufragar metodologicamente e impossibilitar a análise científica aprofundada de qualquer um dos seus elementos.

Mais especificamente, utilizando-se da distinção entre as disciplinas zetéticas e dogmáticas que Tércio Sampaio Ferraz Junior ${ }^{13}$ propõe para divisão do ensino jurídico, poderíamos dizer que, na forma como geralmente se dá seu

${ }^{10}$ CALmON, Pedro. Curso de Teoria Geral do Estado. 6. ed. Rio de Janeiro: Livraria Freitas Bastos, 1964, p. 7.

${ }^{11}$ DALLARI, Dalmo de Abreu. Elementos de teoria geral do Estado. 23. ed. São Paulo: Saraiva, 2002, p. 2.

12 DALLARI, Dalmo de Abreu. Elementos de teoria geral do Estado. 23. ed. São Paulo: Saraiva, 2002, p. 6.

${ }^{13}$ FERRAZ JUNIOR, Tércio Sampaio. Introdução ao Estudo do Direito: técnica, decisão, dominação. 3. ed. São Paulo: Atlas, 2001, p. 41. 
ensino, a TGE - que deveria encaixar-se entre as disciplinas críticas, reflexivas e especulativas - acaba por se tornar uma disciplina dogmática, acentuando mais opiniões com "função diretiva explícita" do que propriamente produzindo conhecimento científico, reflexivo e crítico.

Como consequência indireta, o ensino do Direito se torna refém daquilo que Ulrich Beck ${ }^{14}$ chamaria de a perspectiva do Estado-nação: dissemina-se o entendimento dogmático de que o Estado é uma entidade necessária e absoluta a qualquer área da compreensão do Direito e do ensino jurídico, e que o Direito deve se erguer sempre em consonância com suas diretrizes. Essa observação pode ser comprovada com um rápido abrir de qualquer livro doutrinário de Direito, como demonstraremos. É sempre nas breves introduções às disciplinas, nas poucas linhas que se dedicam ao Estado, que temos alguns curtos - porém significativos - relatos que comprovam essa afirmação. Como exemplo, tomemos a obra de Hugo de Brito Machado ${ }^{15}$, sobre Direito Tributário:

Para viver em sociedade, necessitou o homem de uma entidade com força superior, bastante para fazer as regras de conduta, para construir o direito positivo. Dessa necessidade nasceu o Estado, cuja noção se pressupõe conhecida de quantos iniciam o estudo do Direito Tributário.

Esse talvez seja o desdobramento mais perverso do ensino dogmático de TGE, pois torna a compreensão sobre o Direito limitada, construída e restrita ao Estado, em uma época em que o Estado Moderno ${ }^{16}$ já não mais se constitui na realidade nacional absoluta que antes representava. Ao contrário: com a globalização e o avanço dos meios de comunicação, as fronteiras do Estado Moderno se flexibilizam e colocam em risco a própria existência do Estado-nação.

No entanto, a concepção restritiva na noção de Direito ao Direito positivo, Estatal, é central no estudo do Direito brasileiro. A exemplo disso, boa parte dos livros da disciplina Introdução ao Estudo do Direito - IED iniciam-se por afirmações sobre a natureza humana gregária, e/ou sobre uma origem natural ou sociológica do Estado. Embora esta disciplina introdutória, da mesma forma que a TGE, não seja "em si, uma ciência, mas um sistema de idéias gerais estruturado para atender a finalidades pedagógicas", como observa

${ }^{14}$ BECK, Ulrich. Toward a New Critical Theory with a Cosmopolitan Intent. Oxford: Blackwell Publishing; Constellations, v. 10, n. 4, 2003, p. 453.

${ }^{15}$ MACHADO, Hugo de Brito. Curso de Direito Tributário. 27. ed. São Paulo: Malheiros Editores, 2006, p. 51.

${ }^{16}$ GIDDENS, A. Mundo em descontrole. Rio de Janeiro: Record, 2005, p. 15. 
Paulo $\mathrm{Nader}^{17}$, os conceitos que apresenta influenciam fortemente o universo doutrinário da, assim chamada, Ciência Jurídica.

É o que ocorre, por exemplo, com as obras clássicas de Paulo Nader, Hermes Lima e Arthur Machado Paupério, que dedicam, respectivamente, dez, seis e duas páginas ao fenômeno do Estado e suas relações com o Direito. Essas descrições são geralmente baseadas ou relacionadas aos títulos e autores consagrados da TGE, cujas obras datam de meados do século XX. ${ }^{18}$ A maioria destes autores utiliza conceitos e noções de Estado cuja origem remonta ao século XIX e/ou que foram desenvolvidas até o período da Segunda Guerra Mundial. Portanto, não consideram, evidentemente, as teorias Constitucionais Pós-1945 e o fenômeno da globalização.

Apesar de inadequada para compreensão do fenômeno que se propõe a descrever, a definição de Estado exposta tanto nos textos de TGE quanto nos de IED possui ampla aceitação no meio jurídico. Acredita-se que esta inadequação é um indício do caráter altamente ideológico, dogmático e profundamente enraizado na defesa do Estado-nação no ensino do Direito. É o que vemos na obra de Paupério" ${ }^{19}$, quando este afirma que "o Estado é a maior e a mais importante das sociedades de ordem temporal, abarcando todos os outros grupos naturais, cujos interesses, subordinados ao bem comum, procura defender e promover".

A visão dogmática de Estado apresentada pelos doutrinadores de TGE influencia, portanto, muitos dos autores consagrados no meio jurídicoacadêmico, como é o caso dos já mencionados, em IED. No entanto, não se restringe a isso: como a concepção de Estado é essencial para praticamente todos os ramos do Direito Público, exerce forte influência sobre todos os campos do ensino jurídico e, possivelmente, sobre toda a cultura jurídica brasileira. Essa afirmação é passível de comprovação se observarmos as poucas notas que autores considerados doutrinadores dedicam ao Estado.

Observemos, além da obra de Hugo de Brito Machado, já citada, outros dois exemplos no campo do Direito Público que comprovam nosso argumento: o Direito Processual Civil e o Direito Administrativo. Em ambos, parte-se do pressuposto de que o conceito de Estado é conhecido, baseado no Estudo preliminar da TGE. Na obra Teoria Geral

\footnotetext{
${ }^{17}$ NADER, Paulo. Introdução ao Estudo do Direito. 22. ed. Rio de Janeiro: Forense, 2002, p. 2.

${ }^{18}$ É o caso das obras Elementos de Teoria Geral do Estado, de Dalmo Dallari (1971); e Teoria Geral do Estado de Sahid Maluf (1954).

19 PAUPERIO, Artur Machado. Introdução ao Estudo do Direito. 3. ed. Rio de Janeiro: Forense, 2002, p. 32.
} 
do Processo, José Eduardo Carreira Alvim ${ }^{20}$ dedica-se, por exemplo, a dissertar em duas páginas sobre a necessidade humana de estabelecer um "agrupamento social (...), pois comunidade sem organização é algo inadmissível." Mais à frente, aponta para a importância da solução da lide por parte do Estado, "para que não seja comprometida a paz social e a própria estrutura do Estado, pois o conflito de interesses é o germe de desagregação da sociedade". Da mesma forma, Hely Lopes Meirelles ${ }^{21}$ explica, em pouco mais de meia página, o conceito de Estado, e também os Elementos do Estado. Conquanto deixe em aberto a conceituação em si, define o Estado como tendo os clássicos "três elementos originários e indissociáveis", conforme apresentados na obra de Sahid Maluf: "Povo, Território e Governo soberano."

A partir das obras citadas, é possível perceber a nitidez da hipótese aqui defendida, de que o conceito de Estado presente nestes textos é inadequado à realidade do século XXI. A observação estrita da definição de Estado de Maluf $^{22}$, para quem "a condição de Estado perfeito pressupõe a presença concomitante e conjugada desses três elementos", que seriam "população homogênea, território certo e inalienável e governo independente", nos leva a pensar se existiria algum - pelo menos um - Estado contemporâneo que se adequasse a essas características.

Nesse sentido, o Estado contemporâneo difere em muito daquele Estado-nação sobre o qual se discutiu para as formulações dos principais conceitos da Teoria Geral do Estado. Quando a globalização flexibiliza fronteiras e relativiza nacionalidades, quando a imigração e o intercâmbio cultural se intensificam entre partes antes completamente distantes do mundo e quando as soberanias estatais são colocadas em xeque diante dos riscos transnacionais ecológicos e do terrorismo, coloca-se à prova a própria existência do Estado.

Assim, podemos talvez antecipadamente concordar com Anthony Giddens $^{23}$, no sentido de que

vivemos num mundo de transformações, que afetam quase todos os aspectos do que fazemos. Para o bem ou para o mal, estamos sendo impelidos rumo a uma ordem global que ninguém compreende plenamente, mas cujos efeitos se fazem sentir sobre todos nós.

\footnotetext{
${ }^{20}$ ALVIM, José Eduardo Carreira. Teoria Geral do Processo. 8. ed. Rio de Janeiro: Forense, 2002, p. 1.

${ }^{21}$ MEIRELlES, Hely Lopes. Direito Administrativo Brasileiro. 32. ed. São Paulo: Malheiros Editores, 2006, p. 60.

${ }^{22}$ MALUF, Sahid. Teoria Geral do Estado. 26. ed. São Paulo: Saraiva, 2003, p. 23.

${ }^{23}$ GIDDENS, Anthony. Mundo em descontrole. Rio de Janeiro: Record, 2005, p. 17.
} 
Nesse ponto, precisamos levantar algumas questões, referentes ao método científico e a produção de conhecimento sobre o Estado no século XXI: de que forma se poderia analisar cientificamente a realidade do Estado dentro desse conturbado contexto de transformações sociais, políticas e econômicas? E como seria possível produzir dados e métodos para possibilitar uma visão adequada desses fenômenos?

\section{O problema metodológico: a ciência centralizada no Estado-nação}

A identificação da TGE com a Ciência Política, no título atual da disciplina atribuído pelo MEC, abre perspectivas diferenciadas e mesmo ambíguas para a abordagem de seu conteúdo. Entretanto, uma vez que este conteúdo seja composto por sínteses tão condensadoras que colocam em risco a metodologia adotada, é possível também que seja identificado com algumas das disciplinas que se propõem ao estudo do Estado e da política, em uma perspectiva disciplinar clássica.

Dentre essas, é comum que a TGE se aproxime da Filosofia Política e a da Ciência Política. Conquanto ambas sejam disciplinas imprescindíveis para o estudo do Estado e da Política, ambas comportam diferenças relevantes, métodos e objetivos distintos. Nesse sentido, como indica Norberto Bobbio ${ }^{24}$ :

A questão das relações entre filosofia política e ciência política é um tema de muitas faces, porque, mantendo-se fixo o significado de um dos dois conceitos, isto é, de ciência política - compreendida como estudo dos fenômenos políticos conduzido com a metodologia das ciências empíricas e utilizando todas as técnicas de pesquisa próprias da ciência do comportamento -, se o outro conceito, filosofia política, for usado, como habitualmente ocorre, em significados entre si muito distintos, as relações entre um e outro também se colocarão inevitavelmente de modo distinto.

Mesmo que essas relações entre Filosofia e Ciência Política - as disciplinas clássicas para o estudo do Estado sustentadas pelo autor ${ }^{25}$-possam ser observadas com interesse, observamos que o próprio Norberto Bobbio já apontava para a insuficiência desta divisão clássica disciplinar para abordar as transformações ocorridas nas relações entre Estado e Sociedade. Embora

${ }^{24}$ BOBBIO, Norberto. Teoria Geral da Política: a filosofia política e as lições dos clássicos. Rio de Janeiro: Campus, 2000, p. 67.

${ }_{25}$ BOBBIO, Norberto. Estado, Governo, Sociedade: por uma teoria geral da política. Rio de Janeiro: Paz e Terra, 1987, p. 56-57. 
trabalhando ainda dentro de uma concepção científica e disciplinar clássicas, Bobbio propõe que é preciso examinar o Estado, não apenas sob esses dois pontos de vista, mas também sob o ponto de vista Sociológico e Jurídico, no sentido weberiano. Apropriando-se, assim, do pensamento de Max Weber, o autor defende que a relação entre Estado e Sociedade é concebida hoje de maneira totalmente diferente da forma como era compreendida na Antiguidade Clássica, na Idade Média e no início da Idade Moderna.

Dessa forma, ao invés de procurar entender a Sociedade como parte do Estado, seria preciso fazer o contrário: inverter a relação entre instituições políticas e sociedade. Logo, a sociedade torna-se o "todo", do qual o Estado é a "parte" - aparato coativo com o qual um setor da sociedade exerce o poder sobre outro. Bobbio ${ }^{26}$ aponta, no entanto, para uma leitura que não leva esta mudança às suas últimas consequências. Para o autor, estas transformações apenas conduziriam à ideia de que o Estado como sistema político seria um subsistema, em relação ao todo social.

Ainda assim, essas afirmações confirmam, no mínimo, uma tendência visível na produção acadêmica contemporânea: boa parte dos textos mais relevantes sobre as transformações do Estado no final do século XX e início do XXI vem sendo escrita por sociólogos - em especial autores do campo da, assim chamada, Sociologia Política. O que isso pode significar?

Em princípio, podemos defender que isso reafirma a sentença de que o Estado não pode mais ser compreendido como uma entidade total, a partir da qual todo tipo de conhecimento deve ser produzido. Ao contrário, o Estado passaria a ser apenas uma parte da sociedade - uma sociedade que se estenderia para além das fronteiras nacionais. Para além disso, somos impulsionados a imaginar se essa mudança de perspectiva não representa um indicativo de enfraquecimento dos Estados Nacionais, em particular do modelo de Estado Moderno clássico - baseado no território, no povo e no poder soberano - como definiam os juristas de TGE, e os doutrinadores depois deles.

É por essa razão que acreditamos ser útil uma análise de alguns autores contemporâneos que se propõem a repensar o Estado Moderno no século XXI, a partir da perspectiva das transformações que este sofre no final do século XX. Em particular, propomos aqui analisar textos de Ulrich Beck, professor da Universidade de Munique, e Anthony Giddens, de Cambrigde.

O pensamento de Ulrich Becké, provavelmente, uma das mais destoantes e acirradas revisões críticas das concepções tradicionais do Estado Moderno e, por conseguinte, da própria Sociologia enquanto conhecimento disciplinar

${ }^{26}$ Ibid., p. 60-62. 
restrito às fronteiras, conceitos e instituições do Estado Nacional. Em suas obras e artigos, Beck procura elaborar uma Sociologia Política com perspectivas praticamente revolucionárias para compreensão do fenômeno da globalização e das transformações do Estado no século XXI.

No mesmo sentido, Giddens ${ }^{27}$ sustenta que só é possível entender as transformações pelas quais passa o mundo a partir da observação das relações entre quatro elementos: os avanços tecnológicos nos meios de comunicação, a globalização, as transformações ocorridas na cultura e as mudanças no Estado e na democracia contemporânea. Esses quatro elementos se influenciariam mutuamente, sendo, ao mesmo tempo, causa alimentadora e efeito consequencial uns dos outros. É dessa maneira que aponta os riscos da globalização, ao relacioná-la com os avanços tecnológicos em comunicação, afirmando que "ela põe em jogo outras formas de riscos e incertezas, especialmente aquelas envolvidas na economia eletrônica global".

Contudo, essas perspectivas aparentemente inovadoras não poderiam surgir sem rompimentos. Para formular uma crítica consistente à compreensão tradicional e às visões doutrinárias do Estado seria necessário, primeiramente, entender e rever a metodologia utilizada na construção dos paradigmas sobre os quais elas foram ideologicamente construídas. Só assim seria possível observar quais outras metodologias podemos utilizar para levantar novos paradigmas para a compreensão do Estado no século XXI. É neste sentido que Beck $^{28}$ inicia sua proposta de uma Nova Teoria Crítica e Cosmopolita, atacando aquilo que acredita ser uma das mais poderosas ideias de nosso tempo, no que diz respeito à sociedade e a política: o entendimento de que a sociedade moderna e a política moderna são, respectivamente, a sociedade e a política organizadas em torno do Estado-nação.

Como consequência disso, o autor ${ }^{29}$ identifica no pensamento científico o que chama de nacionalismo metodológico: ou seja, as sociedades são definidas de acordo com as fronteiras dos Estados nacionais, igualando o conceito de sociedade ao de sociedade do Estado-nação. Essa perspectiva pressupõe que a humanidade é naturalmente dividida em um número limitado de nações, que internamente se organizam em determinado número de Estados e externamente erguem fronteiras para distinguir-se de outros Estados-nacionais. Dessa forma, o conhecimento sócio-científico estaria enraizado no conceito de Estado-nação. Não só a Política, mas também

\footnotetext{
${ }^{27}$ GIDDENS, Anthony. Mundo em descontrole. Rio de Janeiro: Record, 2005, p. 15.

${ }^{28}$ BECK, Ulrich. Toward a New Critical Theory with a Cosmopolitan Intent. Oxford: Blackwell Publishing; Constellations, v. 10, n. 4, 2003, p. 453. Tradução livre do autor.

${ }^{29}$ Ibid., p. 453-454. Tradução livre do autor.
} 
o Direito, a Justiça e a História seriam subordinados ao nacionalismo metodológico. Toda a produção das ciências sociais, inclusive os trabalhos de pesquisa empírica - que requerem estatísticas, que são quase que exclusivamente nacionais - estaria submetida a esse princípio.

É a partir da identificação da influência do nacionalismo metodológico na construção da ciência moderna que $\mathrm{Beck}^{30}$ estabelece sua crítica às ciências sociais, em particular à Sociologia clássica. Nesse sentido, sustenta que "a crítica ao nacionalismo metodológico diz respeito aos erros e acertos de uma relação histórica de valores nacionais específicos que os clássicos construíram no imaginário sociológico". Essa influência não teria implicações meramente em "valores e preconceitos, mas sim quanto à ciência, a política de fomento, a pesquisa e a opinião de especialistas".

Uma das grandes dificuldades dessa tese é que ela se propõe a remodelar praticamente todas as categorias sociológicas clássicas. Essas categorias, que o autor ${ }^{31}$ chama de conceitos zumbis, seriam os conceitos apropriados para a época do nacionalismo metodológico, mas que não mais teriam a capacidade de descrever a realidade das fronteiras insólitas entre política, moral e comunidades sociais, e assim falham ao experimento em andamento de criar cidadãos e espaços públicos transnacionais Pós-Westfalianos. Esses conceitos seriam inapropriados para explicar a realidade de uma era de riscos globais ecológicos, econômicos e políticos.

A relação entre a sociologia clássica e as categorias zumbis é explicada por Beck ${ }^{32}$ - de maneira que beira o cômico - no exemplo abaixo, do que representaria, hoje, a categoria "renda familiar" para a Sociologia:

Como se sabe, a renda familiar é uma unidade de referência central e, portanto, uma categoria-chave da análise sociológica. (...) Com ajuda das rendas familiares, que são operacionalizadas, é possível definir as classes, pois é justamente essa renda (...), que serve de indicador da classe social. (...) Mas que é renda familiar hoje em dia? (...) Quanta coisa existe por aí! Os meus filhos, os teus, os nossos; os divórcios, novos casamentos, living-apart-together, diferentes trajetórias profissionais, mobilidade permanente, segundos domicílios, etc. (...) E nesse caos amoroso absolutamente normal, a sociologia tem de responder a uma pergunta aparentemente simples e indispensável para a análise das classes: que é renda familiar?

A renda familiar seria, portanto, um conceito zumbi na sociologia contemporânea: uma categoria que não mais representa a realidade.

30 Ibid., p. 454-455. Tradução livre do autor.

${ }^{31}$ BECK, Ulrich. Toward a New Critical Theory with a Cosmopolitan Intent. Oxford: Blackwell Publishing; Constellations, v. 10, n. 4, 2003, p. 455. Tradução livre do autor.

${ }^{32}$ BECK, Ulrich. Liberdade ou capitalismo. São Paulo: Editora UNESP, 2003, p. 15. 
$\mathrm{Na}$ impossibilidade de definir o que seria renda familiar, Beck ${ }^{33}$ cita o sociólogo francês Jean-Claude Kaufmann, que tenta chegar a definição do que seria um "casal”, visto que "já não se pode definir casal pela certidão de casamento nem pela sexualidade". Diante das mudanças ocorridas nas formas de se estabelecer família num mundo globalizado e em constante transformação, Kaufmann conclui que casal "é quando duas pessoas compram uma lavadora, ao invés de duas".

Nesse ponto é possível fazer uma analogia entre o pensamento de Beck e de Giddens. Para este último, a compreensão das transformações do Estado no século XXI depende da modificação da própria forma como se produz conhecimento. Desse modo, este autor ${ }^{34}$ também se propõe a revisitar o pensamento sociológico clássico, defendendo que seria possível entender e se apropriar da lógica que regia a Sociologia clássica sem, contudo, abrir mão da sua crítica. Assim, nos lembra que a maioria dos fundadores da Sociologia acreditava que "com o maior desenvolvimento da ciência e da tecnologia o mundo iria se tornar um lugar mais estável e ordenado". Segundo ele, essa noção de que "nos tornaríamos todos minúsculos dentes de engrenagens numa vasta máquina social e econômica" era aceita por muitos pensadores e influenciou desde os marxistas até aqueles que se opunham a Marx, e teria influenciado também as formulações de Max Weber.

Questionando o papel da ciência pensado pelos sociólogos no passado, Giddens ${ }^{35}$ afirma que "o mundo em que nos encontramos hoje (...) não se parece com o que eles previram. Em vez de estar cada vez mais sob nosso comando, parece um mundo em descontrole". Além disso, continua o autor: "algumas das influências que, supunha-se antes, iriam tornar a vida mais segura e previsível (...), entre elas a ciência e a tecnologia, tiveram muitas vezes o efeito totalmente oposto".

$\mathrm{Na}$ realidade, a formulação de Giddens sobre tais mudanças completa a tese de Beck: enquanto este se refere às categorias zumbis do pensamento sociológico, aquele aponta para as instituições-casca às quais essas categorias se referem. Para Giddens ${ }^{36}$, a nação, assim como outras instituições - a família, o trabalho, a tradição e a natureza -, sofre diversas modificações. Contudo, elas não desaparecem, mas antes se tornam instituições-casca, ou seja, inadequadas para o papel que se propõem a desempenhar. Essas mudanças, portanto,

\footnotetext{
33 Ibid., p. 15.

${ }^{34}$ GIDDENS, Anthony. Mundo em descontrole. Rio de Janeiro: Record, 2005, p. 14.

35 Ibid., p. 14-15.

36 Ibid., p. 28-29.
} 
Estão criando algo que nunca existiu antes, uma sociedade cosmopolita global. (...) Ela está emergindo de uma maneira anárquica, fortuita, trazida por uma mistura de influências. Ela não é firme nem segura, mas repleta de ansiedades (...). A impotência que experimentamos não é um sinal de deficiências individuais, mas reflete a incapacidade de nossas instituições.

Essa formação de uma sociedade global cosmopolita colocaria em xeque a função dos Estados-nação e entraria em confronto com sua importância e permanência no cenário político mundial. É neste sentido que Giddens ${ }^{37}$ questiona: "são ainda poderosos os estados-nações, e portanto os líderes políticos nacionais, ou estão se tornando em grande parte irrelevantes para as forças que moldam o mundo?" Afinal, a identidade do Estado-nacional que antes era definida diante da diferença dos outros Estados não faria mais sentido neste novo contexto. Diante dos impulsos transformadores da globalização,

as nações tem de repensar suas identidades, agora que as formas mais antigas de geopolítica estão se tornando obsoletas. (...) Após a dissolução da guerra fria, a maioria das nações não tem mais inimigos. (...) quem são os inimigos da Grã-Bretanha, ou da França, ou do Brasil? (...) As nações enfrentam hoje antes riscos e perigos que inimigos, o que representa uma enorme transformação em sua própria natureza.

\section{Conclusões: por uma reformulação da crítica do Estado e do Direito}

Sendo assim, talvez seja possível afirmar uma relação de causa-efeito reflexiva entre os diversos fatores mencionados: uma relação entre a globalização, o Estado-nação, e a ciência que se propõe a descrevê-lo. As transformações geradas pela globalização no final do século XX afetariam diretamente as instituições base do Estado Moderno. Essas se tornariam instituições-casca, que existiriam da mesma forma que antes, mas não representariam nem funcionariam conforme seu sentido original - assim como ocorreria com o Estado-nação, de maneira geral. Por sua vez, a ciência que almeja compreender a relação entre o Estado e essas mudanças seria também produzida com base em conceitos-zumbis, ou seja, conceitos criados pela Sociologia clássica dentro de uma lógica disciplinar, e fundamentados na existência do Estado-nação - pressuposto que não responderia adequadamente à realidade atual de riscos globais e suas implicações políticas.

${ }^{37}$ GIDDENS, Anthony. Mundo em descontrole. Rio de Janeiro: Record, 2005, p. 28. 
O que se faz necessário, então, é uma reformulação da leitura da Sociedade e do Estado. Esta, não deve ser apenas compreendida como a sociedade do Estado-nação, mas deve considerar os elementos que transcendem ao âmbito nacional. O Estado deve ser lido, também, sob nova ótica, que considere não só os elementos internacionais, mas principalmente aquilo que é transnacional, como sugere Anthony Giddens ${ }^{38}$ :

Tal como praticada até agora, a política democrática pressupôs (...) a nação soberana. Sob o impacto da globalização, no entanto, a soberania se tornou nebulosa. (...) Riscos ecológicos, flutuações da economia global, ou mudança tecnológica global não respeitam as fronteiras das nações. Escapam aos processos democráticos.

Sem essa leitura, a interpretação do Estado e, consequentemente, a proposição de uma Teoria do Estado para o ensino do Direito, permanecem reféns daquilo que Ulrich Beck chama de a perspectiva do Estado-nação. Ou seja, o entendimento dogmático de que o Estado é o fundamento maior de todas as organizações sociais e do conhecimento - da Ciência, da Ciência Jurídica e do Direito.

Em termos acadêmicos, podemos dizer que essa tem sido a contribuição do ensino dogmático da Teoria Geral do Estado até aqui. As formulações dos autores tradicionais da disciplina possuem, ainda, ampla aceitação no universo do Direito, apesar de estarem defasadas em relação às transformações do Estado no século XXI e à globalização - conforme procuramos demonstrar aqui. Dessa maneira, a formação do estudante de Direito brasileiro apresenta, desde seu princípio, um caráter doutrinário, ideológico e fundamentado na defesa do Estado-nação.

Assim, podemos afirmar que: se de fato o Estado-nação passa por transformações e o Direito (positivo) é nele fundamentado, é necessário compreender estas transformações - que precisam ser analisadas dentro de uma nova concepção de conteúdo para disciplinas como TGE - para uma análise crítica e um reposicionamento teórico do Direito, a partir de uma outra Teoria do Estado. Caso este esforço não seja empreendido, corre-se o risco de que o ensino do Direito fique engessado em conceitos e noções superadas pela realidade contemporânea.

Enquanto o ensino tradicional da TGE no Direito permanece pautado e centrado em categorias do Estado-nação, a conjuntura político social superou este conceito e está criando novas maneiras de relação entre Estados e

${ }^{38}$ GIDDENS, Anthony. Mundo em descontrole. Rio de Janeiro: Record, 2005, p. 88-89. 
sociedades. Se o Estado transformou-se em outra coisa, o Direito também deve transformar-se, ou corre o risco de ter seus conceitos, categorias e institutos transformados em conceitos zumbis, e as instituições dele decorrentes, em instituições-casca - instituições que permanecem erigidas, no entanto com funções difusas ou simplesmente formais e inadequadas.

Podemos, então, assim resumir essas perspectivas:

(a) o conceito de "Estado" é fundamental para o conhecimento do Direito, em especial para o Direito Público;

(b) o conceito de "Estado" e seus elementos essenciais apresentados nas obras dogmáticas e doutrinárias são baseados nas concepções presentes nas obras de TGE que, por sua vez, são inadequados à realidade do século XXI; (c) logo, todo o estudo do Direito é fundamentado em conceitos inadequados sobre o Estado, fundamentados em um nacionalismo metodológico e na perspectiva do Estado-nação e;

(e) é preciso, portanto, reformular o ensino da TGE a partir da análise da conjuntura atual das relações entre Estado e da Sociedade cosmopolita que o cerca e transforma.

O estudo crítico do Estado e do Direito, sob as perspectivas aqui propostas, aponta para a necessidade de reconhecer as transformações contemporâneas que vêm ocorrendo nas instituições políticas tradicionais. Embora estas não sejam o objeto de estudo do presente artigo, tais mudanças sociais podem ser uma das muitas consequências da utilização de novos paradigmas para a compreensão do Estado no ensino e na prática do Direito. Da mesma maneira, cabe apontar ainda, a transformação das concepções tradicionais da Teoria do Estado pode levar também à necessidade de novas Teorias do Direito - talvez um Direito voltado para as demandas de uma sociedade transnacional e cosmopolita, não restrita às fronteiras, conceitos e instituições do Estado-nação. 


\title{
Theory of the State and Globalization: Research in motion to the critique of dogmatic
}

\begin{abstract}
This paper deals with the construction of knowledge, ideas and concepts used to understand the State and its categories in the teaching of law in Brazil, observed in the work of authors and doctrinal texts traditionally used in the program of the discipline General Theory of the State (Political Science), as described by the Ministry of Education - MEC. Having the problems identified in legal education as a start, it discusses the consequences of the uncritical use of zombie-concepts, with its ideological content centered on the concepts of state and its shell-institutions, inadequate to the reality of the changes occurring in the State during the twenty-first century. It proposes a methodological review of the Theory of the State from the critique of methodological nationalism and the nationstate perspective, as pointed out by Ulrich Beck and Anthony Giddens.
\end{abstract}

Keywords: Theory of the State. Nation State. Globalization. Legal education.

\section{REFERÊNCIAS}

ALVIM, José Eduardo Carreira. Teoria Geral do Processo. 8. ed. Rio de Janeiro: Forense, 2002.

BECK, Ulrich. Liberdade ou capitalismo. São Paulo: Editora UNESP, 2003.

Toward a New Critical Theory with a Cosmopolitan Intent.

Oxford: Blackwell Publishing; Constellations, v. 10, n. 4, 2003.

. O Estado Cosmopolita: para uma utopia realista. Eurozine;

Non! Cultura \& Intervenção, 2002.

. A sociedade Global do Risco: uma discussão entre Ulrich

Beck e Danilo Zolo. Florianópolis: UFSC, 2000.

BOBBIO, Norberto. Teoria Geral da Política: a filosofia política e as

lições dos clássicos. Rio de Janeiro: Campus, 2000. 
. Estado, Governo, Sociedade: por uma teoria geral da política.

Rio de Janeiro: Paz e Terra, 1987.

BONAVIDES, Paulo. Ciência Política. 9. ed. Rio de Janeiro: Forense, 1993.

CALMON, Pedro. Curso de Teoria Geral do Estado. 6. ed. Rio de Janeiro: Livraria Freitas Bastos, 1964.

DALLARI, Dalmo de Abreu. Elementos de teoria geral do Estado. 23. ed. São Paulo: Saraiva, 2002.

DE MATOS, Marcus V. A. B.; SOUZA, Priscila V.; DEMIDOFF, Alexandre. O. Novos paradigmas para a Teoria Geral do Estado: A contribuição da Sociologia contemporânea. In: Jornada Giulio Massarani de Iniciação Científica, Artística e Cultural da UFRJ, 29., 2007, Rio de Janeiro. Anais... Rio de Janeiro: UFRJ, 2007. p. 359.

\section{DE MATOS, Marcus V. A. B. Resumo do Plano de Atividades do}

Monitor. Disciplina de Teoria Geral do Estado. Faculdade Nacional de Direito. Universidade Federal do Rio de Janeiro: Rio de Janeiro, 2006.

DEMIDOFF, A. O.; DE MATOS, M. V. A. B.; MAGALDI, T.; SOUZA, P. V.. Novos paradigmas para a Teoria Geral do Estado: a contribuição do pensamento de Ulrich Beck, Anthony Giddens e Giorgio Agamben para a compreensão do Estado no Século XXI. Projeto de Pesquisa. Universidade Federal do Rio de Janeiro - UFRJ. Rio de Janeiro, 2007. $29 \mathrm{p}$.

FERRAZ JUNIOR, Tércio Sampaio. Introdução ao Estudo do Direito: técnica, decisão, dominação. 3. ed. São Paulo: Atlas, 2001.

FONSECA, Ricardo Marcelo (Org.). Repensando a Teoria do Estado. Belo Horizonte: Fórum, 2004.

GIDDENS, Anthony. Política, Sociologia e Teoria Social: encontros com o pensamento social clássico e contemporâneo. São Paulo: Editora UNESP, 1998. 
. Mundo em descontrole. Rio de Janeiro: Record, 2005.

LIMA, Hermes. Introdução à Ciência do Direito. 16. ed. Rio de Janeiro: Livraria Freitas Bastos, 1966.

MACHADO, Hugo de Brito. Curso de Direito Tributário. 27. ed. São Paulo: Malheiros Editores, 2006.

MALUF, Sahid. Teoria Geral do Estado. 26. ed. São Paulo: Saraiva, 2003.

MEIRELLES, Hely Lopes. Direito Administrativo Brasileiro. 32. ed. São Paulo: Malheiros Editores, 2006.

NADER, Paulo. Introdução ao Estudo do Direito. 22. ed. Rio de Janeiro: Forense, 2002.

PAUPERIO, Artur Machado. Introdução ao Estudo do Direito. 3. ed. Rio de Janeiro: Forense, 2002.

VIEIRA, José Ribas. Introdução à Teoria do Estado. Porto Alegre: Síntese, 1999.

目 Recebido: março/2012. Aprovado: fevereiro/2013. 